\section{ADIPOSIS DOLOROSA.}

\section{JULE B. FRANKENHEIMER, M.D. SAN FRANCISCO.}

Since the original papers of Dercum $(1888,1892)$ only about 45 cases of adiposis dolorosa have been recorded in the literature. It is rather difficult to make a complete study of these cases, for some of them are doubtful and some are reported too briefly. The rare occurrence of this condition and the haze which still surrounds it prompts me to report the following case from the City and County Hospital, service of Dr. J. O. IIirschfelder, to whose kindness I am indebted for the opportunity to study the patient:

Patient.-Mrs. M. E. F., housewife, was born in Ohio, 77 years ago. The family history is negative as to tuberculosis, (ancer and alcoholic excesses. The father, at the age of 35 , was insane for six weeks on account of business troubles; he recovered completely and died at the age of 75 years. One of three brothers was paralyzed in the legs for one year; he has gradually recovered, though not entirely.

History.-Patient married at 24 years and lived with her husband, who said he had had syphilis twenty years. Six weeks after marriage, a rash appeared and later the hair on lier head feel out in patches. She has had five children, all living and well. There was one miscarriage before the first child was born. Menstruation began at 14 years. The periods were always regular, lasted eight days, and were never painful. Excessive amounts of blood were lost. The menopause began at 62 years, and continued without any symptoms. Sexual induIgence was excessive. The patient's habits are good. She has worked hard and does not use alcohol. She had mumps and measles when a child, malaria twice. About two years ago she had rheumatism (?) in the legs without joint enlargement. She says that one year ago she had an attack like the fresent one, when her arms became numb. This lasted three days. These numb spells would come on for an hour or two occasionally.

Present Illness.-At present she complains of pain in the neck, lower back and feet. There is a feeling of general lassi. tude and her arms and legr feel heavy, and occasionally numb. There are painful areas on the legs on pressure. She has had palpitation for years, and is somewhat short of breath at times Ifer feet have been swollen twice. She voids urine once or twice at night. Three weeks ago the present trouble began with headache and vomiting. She would vomit several times a day, with no preceding nausea. The vomiting was projectile in charactcr; only occasionally after these attacks would she feel sick. This Iasted several days, and then gradually stopped one week ago. She complained of a severe, dull headache all the time-it seemed to be worse on the top of the head. The patient is very forgetful; she can not think of the word she wishes to use. Her eyesight has been failing during the last five years.

Examination.-The patient was in a stuporous condition, aprthetic. She could raise herself in bed. She was found to be well-developed, poorly nourished, slightly cyanotic and dyspneic. The skin, is cool and dry. The movements of the eyes were normal, and the pupils equal; they reacted to light and accommodation. There was no paresis of the muscles of head or face. The tongue was dry, red and coated, the papillæ were enlarged toward the tip; there was a granular condition of the soft palate and pharynx. The cervical glands were slightly enlarged; the thyroid was palpable and the middle lobe was enlarged. The vessels in the neck pulsated. There was enlargement principally downward and outward of the area of cardiac dulness. Loud systolic murmurs could be heard at the apex and were transmitted to the axilla; they were also heard over the aortic area and were transmitted upward. The purlse was irregular in force and rhythm; the pressure was low. The chest was well-formed; the lungs were negative. There was no enlargement of the liver; the spleen was not palpable. The abdomen was very pendulous, with a thick fatty wall of jelly-like consistence. The inguinal and epitrochlear glands were not enlarged. There was slight edema of the feet and legs. The knee jerks were present; the plantar reflex was lively with flexor response of big toe. The abdominal reflex and the reflexes of the upper extremities were not present. No tenderness was found over the nerve trunks. Owing to the condition of the patient's mind great difficulty was experienced in obtaining results in testing sensation; however, there seemed to be an hypesthesia, principally of the arms and legs, though the trunk was also involved. The localizing sense was good; co-ordination was good; the stereognostic sense was not much impaired. An examination of the background of the eyes and of the field of vision could not be made on account of cataract in both eyes. The special senses were otherwise unimpaired. Around both legs, just above the malleoli was a cuff of fatty tissue about $6 \mathrm{~cm}$. wide and $3 \mathrm{~cm}$. high, which was rather painful on pressure. The fat was of firm consistence, and on palpation gave the impression of a mass of worms. On the inner sides of the knees and thighs there were large deposits of fatty tissue, painful on pressure. Iarge masses of fat, not so tender as the preceding, were found on the outer sides of the thighs and gluteal regions. The abdominal fat deposits were diffuse and only moderately sensitive. When the upper arms were raised a flap of diffuse fat hung from them; they were also sensitive on pressure. There was a large ecchymotic spot on the outer side of the right arm where pressure was used in raising the patient. All the muscles of the body seemed atrophied. The muscular power was much diminished; dynamometer, right, 30 ; left, 20 . Patient could not raise herself to a sitting posture in bed.

Blood Examination: Hemoglobin, 75 per cent.; red cells, 4, 700,000 ; white cells, 9,500. Differential count: Polymorphonuclears, 68 per cent.; small mononuclears, 23 per cent; large mononuclears, 7 per cent.; eosinophiles, absent; mast cells, 2 per cent.; coagulation time, 2 minutes and 10 seconds.

Urine: Sp. gr., 1.020, acid; albumin, 1 per cent.; no sugar. Microseopically, a few granular casts and pus cells were found.

Treatment.-The patient was given 5-grain thyroid tablets, one tablet three times daily. There has been marked improvement. The mind has become much clearer and she is now able to sit up in a chair. The masses of fat have diminished considerably in size and have become softer and less painful to pressure. Other measures such as diet, massage and hydrotherapy were not resorted to.

\section{ETIOLOGY.}

Cases of adiposis dolorosa have occurred in families. Cheevers $^{1}$ reported a case in a male whose father and sister both had the same disease, and Hammond ${ }^{2}$ reportcd two cases occurring in sisters. Women are affected much more frequently than men. A collection of the cases in the literature ${ }^{3}$ which was accessible showed the ratio to be about six women to one man. The age of onset is variable, the youngest patient being 12 years old and the oldest 78 years. The majority of cases in men occur between the ages of 30 and 40 ; in women between 30 and 50 years. Neuropathic and alcoholic personal or family histories have been noted, while syphilis and trauma figured in a few cases. Disturbance of the sexual organs, such as excessive menstrual flow and uterine hemorrhage, have frequently been found. Spiller's case dated from pregnancy, while Schlessinger's case occurred after an abortion. The menopause seems to predispose to the disease.

\section{PATHOLOGY.}

Only five autopsies are recorded in the literature at my disposal. In these, as well as in a few in which

1. Brit. Med. Jour.. 1904, i.

3. The following articles may be of interest in addition to those referred to elsewhere: Weiss : Centrlb. f. d. Grenzgeb. Med. et Chir., 1904, vil. Gordonier: Vermont Med. Monthly, 1903, ix. Marcou: Archiv. Gen. d. Med., 1903, ii. Ballet : Presse Méd., 1903, i. Hall and Walbrach: Am. Jour. Med. Sc., 1904. Schwenkenbecher : Deutsch. Archiv. f. klin. Med., 1904, lxxx. Debove : Archiv Gen. de
Med., 1903, 11. Fulconis: Thesis, Lyons, 1904. Fuchs : Wiener klin. Med., 1903, 11. Fulconis : Thesis, Lyons, 1904. Fuchs: Wiener klin.
Wochschr., 1905. Wingate: Wisconsin Med. Jour., 1905, iv, 6. 
siuall portions of tirsue have been excised, the fatty tissue $\mathrm{js}$ of normal structure. In one of Dercum's pat conts there was an interstitial neuritis, with a moderate sclerosis of the columns of Goll. The sclerosis, in all probability, was a concomitant affection. The most constant lesions appeared in the thyroid gland, which was cnlarged and calcareously infiltrated in two cases, was partially atrophied in two cases, and was normal in one cas?.

The other important and significant lesions were found in the pituitary body, which was abnormal in three of the five cases. There was enlargement and gliomatous degeneration in two cases, and adenocarcinoma in one.

It is of some interest to compare the condition of the thyroid and pituitary body in adiposis dolorosa and acromegaly.

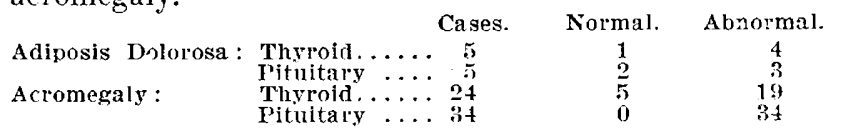

Clinically, adinosis dolorosa is a disease characterized by four cardinal swmptoms: (1) The accumulation of fat, usually localized; (2) pain and tenderness in the fatty swellings; (3) asthenia, and (4) psychic disturbance.

The abnormal deposition of fat may be nodular, diffuse but circumscribed, or generalized diffuse. It may vary in consistence from rather soft (pultaccous) to firm; the latter variety, on palpation. sometimes giving the impression of a mass of closely intermingled worms. These masses are ustally symmetrical, but may be irregular in size and distribution. The face, hands and feet are not involved. The lipomatosis may be preceded, accompanied or followed by the pain; usually they occur synchronously, though occasionally the lipomatosis may precede the pain by years.

The pain may be spontaneous, or caused and increased by pressure and movement. It may be sharp or dull, and is deseribed as neuralgic or rheumatic. It does not follow the course of the nerves, and is seldom constant. It may be paroxysmal in character, and is sometimes dependent on movement, excitement, digestive disturbances, insomnia and changes in the weather.

The asthenia is variable; it may be very marked. There is no reaction of degeneration in the muscles. and there are no paralyses. In a majority of cases, the knce jerk and tendon reflexes in general are diminished or absent. The psychic phenomena consist in marked apathy and depression, great irritability and occasionally fementia.

Other symptoms include headache, disturbance of sensation, paresthesia and usually an hypesthesia to touch, pain and temperature. Lessened perspiration is the most common and important of the vasomotor phenomena; though cyanosis of the extremities, ccchymoses, tronhic ulcers, dermographia and vesicles on the palms and soles (during attacks of pain) mav occur.

The disease is rarely fatal and death is due to some intercurrent affection. Exacerbations occur in the form of paroxysms of pain and increase in size of the fatty accumulations which become more firm. After the paroxysm, the pain lessens in severity and the masses decrease in size; however. there is always a permanent increase of the fatty deposits after each exacerbation.

$\mathrm{Mr}$ casc is typical and could be classified as of the mixnd form: that is. localized (diffuse) and generalized (diffuse). The asthenia was very marked and striking, while the psychic phenomena consisted in an apathy. with occasional short periods of irritability, the "causeless quarreling" of which Dercum speaks. The pain was usually described as "rheumatic," though at times the patient complained of "neuralgia." Pressure over the fatty deposits always caused pain, more or less severe.

The lack of perspiration, the later development of a small bed-sore, and the echrmoses resulting from slight injuries were the lesser symptoms which occurred. Unfortunately, the history was obtained with great difficulty, and the time and sequence of the occurrence of the difierent symptoms is unknown.

\section{SUMMARY.}

If we compare the incidence of sex in patients affected with obesity, adiposis dolorosa and diseases of the thyroid gland, such as myxedema and exophthalmic goiter, we find that the disproportion between the two sexes in the incidence of obesity is not at all comparable to the disproportion which occurs in adiposis dolorosa, exophthalmic goiter and myxedema; the ficures for the three last named diseases showing a striking similarity, as follows:

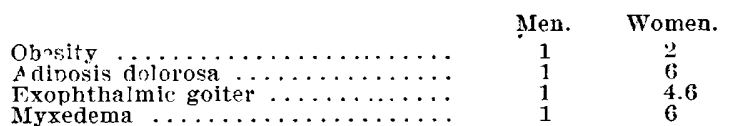

That the thyroid is involved in adiposis dolorosa is rvidenced by the patholog:c findings (atrophy, hypertrophy), and the presence of myxedematous symptoms, mich as a lack of perspiration, and changes in the skin. The psychic condition (apathy) is also similar to that in myxedema, while the positive therapeutic results with thyroid extract should likewise be considered. From his study of adiposis dolorosa, von Schroeter concludes that it is a "dysthyroidismus," while Pineles considers the disease an expression of disturbed function of "numerous blood glands, including 'hypothyroidismus,' genital atrophy and changes in the hypophysis." In regard to the disease being due (among other causes) to hypothyroidismus, the concomitance of exophthalmic goiter would indicate that the cause is more of a dysthyroidismus than a hypothyroidismus; that is also suggested by the fact that in cretins (hypothyroidismus) there is an atrophy of the thyroid and genitals with no symptoms of adiposis dolorosa.

That the genitals are a factor in producing the disease can only be proved by further study. It would be rather interesting in the light of later knowledge. to investigate narticularly the condition of the genital organs. Billings ${ }^{4}$ patient was sexually impotent two years preceding the onset of the disease, while in Staley's patient the ovaries har been removed some time previously. Howcrer, significant symptoms and facts are: (1) Excess've monstrual flow; (2) uterine hemorrhage; (3) early menopause; (4) commencement of disease at mononause: (5) exacerbation following abortion; (6) inception of disease at deliverv.

In conclusion I would suggest that adiposis dolorosa, like acromegaly, is a dystrophy, the one affecting the fatty, the other the osscous structures; and that there is present a toxemia dependent on a drsthrroid:smus and the disturbed function of the pituitary body and the genital organs.

4. Illinois Med Tour. April, 1903

5. Brit. Med. Jour., 1905, . i. 